\title{
Mudstones in the Scanning Electron Microscope
}

SIR - This note describes some simple techniques developed during a study of laminated lower Palaeozoic mudstones using a scanning electron microscope. The instrument was used to show minerals and fabrics not visible using an optical microscope, either because they are too small to be resolved, or because they are obscured by the semi-opaque material common in thin sections of clay rich rocks. The mudstones examined consisted mainly of chlorite, illite and micas.

Stubs were prepared by cutting short rods of rock, scoring round the equatorial circumference, and (with the two ends in two pairs of pliers) snapping the rod in half, taking care that the fractured surfaces did not rub against one another. The specimens were cleaned briefly in an ultrasonic bath and mounted with Durafix. The sides of the mounted specimens were painted with silver dag, and the specimens coated with aluminium.

Other preparation techniques, such as cutting or fine polishing, with or without subsequent intense ultrasonic cleaning, heating, or etching were much less revealing than fractured surfaces. Polishing gave the surface a smeared appearance, apparently due to shearing of the soft clay minerals.

It was not possible to identify minerals on fractured surfaces solely from their morphology. However, a series of selective etchings of the same surface allowed all the minerals present to be characterised. Photomicrographs were first taken of the fractured surface, including sufficient low magnification micrographs to permit relocation of details. The specimen was then taken off the stub by dissolving the Durafix in acetone, and the aluminium coating removed with dilute sodium hydroxide. It was then etched, cleaned and mounted as before, and rephotographed. No damage to clay minerals was observed resulting from the brief immersion in sodium hydroxide.

The following etching reactions were used. Their effect was confirmed by repeating the process on crushed samples and making an $x$-ray diffraction analysis.

1. Calcium carbonate and apatite removed by dilute acetic acid.

2. Iron oxides removed by heating with sodium dithionite and sodium citrate buffered with sodium bicarbonate (Mehra, O. P. \& Jackson, M. L., 1960: Iron oxide removal from soils and clays by a dithionite-citrate system buffered with sodium bicarbonate. Clays Clay Miner., 7, 317-327.).

3. Chlorite and dolomite removed or etched by 15 minutes boiling with $20 \%$ sulphuric acid.

4. Fusion with sodium bisulphate etches other platy minerals but does not attack quartz and feldspar. (Finely divided quartz may fall out during this treatment.)

With an elementary knowledge of crystal form and cleavage, this allowed a complete mineralogical determination of scanning electron micrographs of lower Palaeozoic mudstones.

The examination of younger rocks, with a greater range of clay minerals, presents greater problems. The simple procedure of selective etching needs to be supplemented by the more time consuming microprobe analysis. The need to prepare dry samples also adds complications.

I am grateful for the use of the scanning electron microscope at the School of Environmental Sciences, University of East Anglia, and to Professor B. M. Funnell and Mrs. June Irvine for discussion. This work was carried out during the tenure of a research fellowship from Jesus College, Cambridge. 